\title{
Learned Helplessness, Psychological Wellbeing, and Proenvironment Care Behavior among Victims of Frequent Floods in Kerala
}

\author{
Lijo Kochakadan Joy J' Manu Ramachandran² Sanju George ${ }^{1}$
}

\footnotetext{
${ }^{1}$ Rajagiri Centre of Behavioural Sciences and Research, Rajagiri College of Social Sciences (Autonomous), Rajagiri, Kalamassery, Kochi, Kerala, India

2Department of Psychology, Prajyoti Niketan College, (Govt. Aided and Affiliated to the University of Calicut), Pudukad, Thrissur Dt., Kerala, India
}

J Neurosci Rural Pract:2021;12:137-144

\begin{abstract}
Address for correspondence Sanju George, Rajagiri Centre of Behavioural Sciences and Research, Rajagiri College of Social Sciences (Autonomous), Rajagiri, Kalamassery, Kochi, Kerala, 683 104, India (e-mail: sanjugeorge531@gmail.com).
\end{abstract}

\section{Abstract}

Keywords

- learned helplessness

- psychological wellbeing

- proenvironment care behavior

- victims of frequent floods
Background In 2018 and 2019, there were floods in the coastal regions of Kerala. Many individuals and families were victims on both these occasions; these floods had devastating impact on individual psychological wellbeing, their financial stability, and on overall family wellbeing. Furthermore, many people in vulnerable geographical areas still live in uncertainty and fear. In this context, our study examined whether continuous victimization of natural calamities, like floods in Kerala, leads to the development of learned helplessness and decreased psychological wellbeing among those affected. We also studied whether proenvironment care behavior increased among flood-affected individuals.

Materials and Methods We studied 374 heads of families in Kerala, selected through the Quota sampling method. They belonged to the following three groups: (1) flood-affected only once (OFA, $n=124)$, (2) flood-affected twice (TFA, $n=124$ ), and (3) never flood-affected (NFA, $n=124$ ) households. The key variables of learned helplessness, psychological wellbeing, and proenvironment care behavior were measured using learned helplessness scale, psychological wellbeing scale, and the environmental behavior scale, respectively.

Statistical Analysis The Kruskal-Wallis test was used to analyze the data for independent groups.

Results Learned helplessness was found to be high among the TFA group. Psychological wellbeing and proenvironment care behavior were high among the OFA group as compared with the TFA group. The NFA group had higher learned helplessness in comparison to the OFA group, and psychological wellbeing and proenvironment care behavior were low when compared with the TFA group.

Conclusion We conclude that surviving a moderate amount of risk is perhaps necessary for better psychological wellbeing and that too many or too few risks in life are detrimental to good psychological health. Immediate psychological support among victims of natural calamities and periodic examination of well-being and psychological interventions among people who are vulnerable for frequent victimization of natural calamities have to part of disaster management related to natural calamities.
DOI https://doi.org/ $10.1055 / \mathrm{s}-0040-1721566$ ISSN 0976-3147. (c)2020. Association for Helping Neurosurgical Sick People.

This is an open access article published by Thieme under the terms of the Creative Commons Attribution-NonDerivative-NonCommercial-License, permitting copying and reproduction so long as the original work is given appropriate credit. Contents may not be used for commercial purposes, or adapted, remixed, transformed or built upon. (https://creativecommons.org/licenses/by-nc-nd/4.0/).

Thieme Medical and Scientific Publishers Pvt. Ltd. A-12, 2nd Floor, Sector 2, Noida-201301 UP, India 


\section{Introduction}

In recent years, nature has become unpredictable and humans have not been able to accurately forecast weather conditions such as extreme winter, heat, and rain. Natural calamities have become common at the peak of weather seasons and unexpected hurricanes, floods, and landslides result in loss of lives, damage of personal property, loss of pets and livestock, agricultural loss, loss of employment days, and reduced agricultural and industrial productivity. ${ }^{1,2}$ Since there is often very little time to prepare for such natural calamities, the cataclysmic effects caused are huge and mostly irreplaceable. In addition to the above-listed negative consequences, there are also secondary level damages including psychological problems among victims and their families, their psychological wellbeing, finances, and subsequent epidemics with its resultant impact on community health.,4

Natural disasters can result in a range of physical (injuries, infections, and death) and economic consequences. Such negative consequences can often lead to severe adverse psychosocial consequences. ${ }^{5}$ It has been found that anxiety, depression, posttraumatic stress disorder (PTSD) and suicides occur in the immediate and long-term aftermath of floods, hurricanes, and earthquakes. ${ }^{6-8}$ Mental health problems are two to three times higher among the victims of natural calamities as compared with the general population. ${ }^{9,10}$ For example, Krug et al found that in the years following a natural disaster, suicide rate kept increasing.?

A study of the victims of a supercyclone in Odisha, India (1999), found that almost $80 \%$ of the participants were vulnerable to psychiatric disorders. ${ }^{11}$ Among various psychiatric conditions, the most prevalent psychological issues were anxiety disorders (57.5\%), depression (52.7\%), and PTSD (44.3\%). The direct causes reported included physical injury, degree of exposure, and loss of house and properties due to calamity or evacuation, death of family members, death anxiety, increased stress and hopelessness. It was also noted that certain factors made a community more vulnerable: extremes of age (children and the elderly), low socioeconomic status, lower educational level, unemployment, and past psychiatric history. ${ }^{11}$ Similarly, a study of the victims of earthquakes in Iran found that losses (of homes, families, relatives, and friends) experienced complicated grief. ${ }^{12}$ So too, studies of victims of the 2004 Tsunami in India reported that PTSD was highly prevalent among the survivors who had lost their family members, neighbors, community life, and house and properties. ${ }^{13,14}$

Just as in earthquakes, cyclones, and tsunamis, the trauma and psychological consequences are similar in flood-affected people. A study from the United Kingdom found that emotional trauma was very high among victims of floods. ${ }^{15}$ This study found that a significant number of participants met diagnostic criteria for anxiety (24.5\%), PTSD (27.9\%), and depression (35.1\%).15 Another study of flood victims in the United Kingdom found increased levels of negative emotions, salience of climate change, and risk perception. ${ }^{16}$ Similarly a study from India among victims of flood and landslide survivors of Uttarakhand reported a high prevalence of psychological morbidity in the postdisaster period, and age was found to be directly proportional to depression, anxiety, stress, and negative outlook about the future among survivors. ${ }^{17}$ Othman et al studied victims of floods in Malaysia and found that flood victims experience PTSD and poor life quality. ${ }^{18}$

It can be argued that the psychological trauma tends to be higher if people are exposed to repeated natural calamities. However, some people are forced to continue to live in such vulnerable and risky geographical areas (prone to floods, cyclones, or landslides), since their homes, land and other properties, and their communities (neighbors, relatives, and friends) exist there. However, continuing to live in such "risky" localities comes at the cost of risking their belongings, livelihood, and lives. Further, these people also tend to live in chronic fear of further losses and being at the mercy of unpredictable natural events. A study of the victims of multiple earthquakes in Naples, Italy (1980 and 1983/1984) found that psychological distress was higher even after 7 years of the disaster event. They cited having to be evacuated and the financial losses incurred as the main reasons for the psychological distress. ${ }^{19}$ Similarly in the United Kingdom, researchers have concluded that repeated exposure to natural calamities and its related economic and emotional consequences can cause psychological disorders. ${ }^{15}$ Another study by Stanko et $\mathrm{al}^{20}$ among people who were exposed to multiple disasters (floods in 2005 and 2016) in Baton Rouge, Louisiana, noted increased rates of anxiety, depression and posttraumatic stress.

Kerala, located on the South Western coast of India, has a population of approximately 3.3 crore. The months of August 2018 and 2019, brought the most devastating and terrifying floods to Kerala. The heavy unremitting monsoon rain continued for days and caused large-scale flooding and landslides in all 14 districts of Kerala. It was estimated to have affected approximately 5.4 million people. Landslides in hilly areas accompanied the floods and this further added to the scale of the catastrophe. As per the official record of Government of Kerala, in a span of 30 days, 342 landslides were reported; 433 people lost their lives and many more were missing; thousands of houses were damaged; 15 million people were in relief camps; and long stretches of roads and many were bridges damaged. Apart from this, people also lost their shops, offices, land, money, agriculture, cattle, belongings, and important personal documents. It was one of the most calamitous disasters India had ever faced and hence was declared a "level-3 calamity of a severe nature" by the Indian Government. ${ }^{21}$

All these created a huge negative psychological impact on the lives of many people. These floods had a devastating impact on the psychological and economic wellbeing of affected individuals and families. Many people in vulnerable geographical areas continue to live in uncertainty and fear. A study conducted immediately after the flood (2018) in Kerala found that participants had undergone severe psychological trauma. The study found that majority of the participants has high level of anxiety, stress, and depression. ${ }^{22}$ Then in 2019, there were severe floods again and people faced cumulated 
trauma while still in recovery from the 2018 floods. In this context, our study aimed to examine whether continuous victimization of natural calamities in Kerala leads to the development of learned helplessness and decreased psychological wellbeing among those affected.

In the present study, we also looked at whether proenvironment care behavior increased among flood-affected individuals. There are studies which also looked at levels of environmental concern among victims of natural calamities. Van der Linden ${ }^{23}$ showed a positive correlation between experiencing severe weather events and environmental risk perception. Similarly, Li et a ${ }^{24}$ found that people made more proenvironmental donations if they interpreted increases in local temperature as because of global warming.

\section{Methods}

\section{Sample}

This study was conducted among 374 heads of families in Kerala. There were following three groups: (1) once flood-affected (OFA, $n=124$ ), (2) twice flood-affected (TFA, $n=124$ ), and (3) never flood-affected (NFA, $n=124$ ) households. Heads of families included men $(n=278)$, women $(n=$ $90)$, and transgender people $(n=4)$. Study data were collected from Thrissur, Wayanad, Ernakulam, Malappuram, and Calicut districts of Kerala. All the participants were family heads and primary earning members of their families. The occupational status of the participants were as follows: farmers (55), small-scale businessmen (79), daily wage workers (132), and employees in the private sector (93) and government sector (13). The age of participants ranged from 25 to 45 years. The average age of participants was 38.26 years. The education status of participants ranged from upper primary level to graduate level (upper primary: 23, secondary: 99, higher secondary: 146 , undergraduate: 72 , and postgraduate: 32). Participants who had any sensory or motor disability and psychological morbidity (subjective or diagnosed) were excluded from the study. Similarly, those who were staying away from their families for occupational or interpersonal reasons were also excluded ( $\mathbf{-}$ Table $\mathbf{1}$ ).

\section{Measures}

Learned helplessness, psychological wellbeing, and environmental behavior were measured using the scales mentioned here.

\section{Learned Helplessness Scale}

Learned helplessness can be defined as a condition in which a person suffers from a sense of powerlessness, resulting from a traumatic event or repeated failure to succeed. The objective of this scale is to measure learned helplessness. It has 20 items and the responses can be on a 4-point scale ranging from 1 (strongly agree) to 4 (strongly disagree). A low score indicates high level of helplessness and this scale has sufficient reliability and validity. ${ }^{25}$

\section{Psychological Wellbeing Scale}

This scale assesses six different aspects of happiness and psychological wellbeing such as autonomy, environmental mastery, personal growth, positive relations with others, purpose in life, and self-acceptance. This scale has 18 items and the response options are presented on a 7-point scale ranging from 1 (strongly agree) to 7 (strongly disagree). A high score indicates a high level of psychological wellbeing. The scale has an adequate level of reliability and validity. ${ }^{26}$

\section{Environmental Behavior Scale}

This scale is used to measure proenvironment care behavior. It explores the predictive power of connectedness to nature, environmental concern, and ecological worldview, and its potential domains with the examination of the multidimensional structure of environmental behavior. It consists of 22 items and the response options range from 1 (strongly agree) to 5 (strongly disagree). Subscales include consumption, environmental action, political action, recycling, household settings, and transportation. A low score is suggestive of a high level of proenvironment care behavior. The scale has an adequate level of reliability and validity. ${ }^{27}$

\section{Data Collection}

All the above scales were translated to Malayalam language (the language spoken in Kerala) and back translated. To ensure the adequacy of translation, original scale and back translation were verified by a bilingual subject expert. The rating scales were administered to the participants selected as per the inclusion and exclusion criteria. The quota sampling method used to include participants in in the categories of family heads such as NFA, OFA, and TFA. Participants required approximately 40 minutes to complete the questionnaires.

All the participants were informed about confidentiality, the importance of voluntary participation, quality of response, and academic and research use of the data. We informed the study participants about the purpose of the study and communicated the results where they asked for it.

Table 1 Distribution of family heads based on family income and flood victimization

\begin{tabular}{|l|l|l|l|l|l|}
\hline Flood victimization & Never flood affected & Once flood affected & Twice flood affected & Total \\
\hline \multirow{2}{*}{$\begin{array}{l}\text { Family } \\
\text { income }\end{array}$} & High & 15 & 52 & 48 & 115 \\
\cline { 2 - 7 } & Medium & 94 & 36 & 30 & 160 \\
\cline { 2 - 6 } & Low & 15 & 36 & 46 & 97 \\
\hline Total & 124 & 124 & 124 & 372 \\
\hline
\end{tabular}




\section{Data Analysis}

The normality of the variables in three groups (NFA, OFA, and TFA) was examined using the Shapiro-Wilk Test ( $\bullet$ Table 2).

Since the variables were not normally distributed $(p<0.05)$, we used the Kruskal-Wallis Test for independent groups.

\section{Results}

The results of testing hypotheses using the Kruskal-Wallis test are given below ( $\mathbf{- T a b l e ~} \mathbf{3}$ ):
There was a significant difference in the level of learned helplessness among groups ( $K=203.118, p=0.0005$ ). All pair wise comparisons were also significant. High levels of helplessness was experienced by TFA group of family heads, followed by the NFA and OFA groups ( - Table 4 ).

There were significant differences among the three groups in all dimensions and the total scores of psychological wellbeing. This high score indicates higher levels of psychological wellbeing. The common trend was that the OFA group had higher levels of psychological wellbeing followed

Table 2 Result of normality of variables such as learned helplessness, psychological wellbeing, and environment behavior among participants

\begin{tabular}{|c|c|c|c|}
\hline Variables & NFA & OFA & TFA \\
\hline Learned helplessness & $0.932^{\mathrm{a}}$ & $0.709^{\mathrm{a}}$ & $0.875^{\mathrm{a}}$ \\
\hline Self-acceptance (PWB) & $0.894^{\mathrm{a}}$ & $0.859^{\mathrm{a}}$ & $0.939^{a}$ \\
\hline Purpose in life (PWB) & $0.974^{\mathrm{a}}$ & $0.950^{\mathrm{a}}$ & $0.931^{\mathrm{a}}$ \\
\hline Positive relations with others (PWB) & $0.946^{a}$ & $0.555^{\mathrm{a}}$ & $0.917^{\mathrm{a}}$ \\
\hline Personal growth (PWB) & $0.927^{\mathrm{a}}$ & $0.637^{\mathrm{a}}$ & $0.838^{\mathrm{a}}$ \\
\hline Environmental mastery (PWB) & $0.975^{\mathrm{a}}$ & $0.946^{\mathrm{a}}$ & $0.964^{\mathrm{a}}$ \\
\hline Autonomy (PWB) & $0.949^{a}$ & $0.673^{\mathrm{a}}$ & $0.897^{\mathrm{a}}$ \\
\hline Psychological well-being (PWB) & $0.931^{\mathrm{a}}$ & $0.871^{\mathrm{a}}$ & $0.951^{\mathrm{a}}$ \\
\hline Environmental action (EB) & $0.851^{\mathrm{a}}$ & $0.589^{\mathrm{a}}$ & $0.949^{a}$ \\
\hline Political action (EB) & $0.911^{\mathrm{a}}$ & $0.633^{\mathrm{a}}$ & $0.826^{a}$ \\
\hline Recycling (EB) & $0.923^{\mathrm{a}}$ & $0.606^{\mathrm{a}}$ & $0.783^{\mathrm{a}}$ \\
\hline Transportation (EB) & $0.923^{\text {a }}$ & $0.554^{\mathrm{a}}$ & $0.828^{\mathrm{a}}$ \\
\hline Household setting (EB) & $0.921^{\mathrm{a}}$ & $0.631^{\mathrm{a}}$ & $0.965^{\mathrm{a}}$ \\
\hline Consumption (EB) & $0.911^{\mathrm{a}}$ & $0.602^{\mathrm{a}}$ & $0.840^{\mathrm{a}}$ \\
\hline
\end{tabular}

Abbreviations: EB, environment behavior; NFA, never flood affected; OFA, once flood affected; PWB, psychological wellbeing; TFA, twice flood affected. ${ }^{\mathrm{a}} \mathrm{p}<0.01$.

Table 3 Results of Kruskal-Wallis test of comparing learned helplessness of family heads belonging to households in Kerala

\begin{tabular}{|l|l|l|l|l|l|l|l|}
\hline \multirow{2}{*}{ Variable } & \multicolumn{3}{|c|}{ Mean } & \multicolumn{3}{c|}{ Mean rank } & \multirow{2}{*}{ OFA } \\
\cline { 2 - 7 } & NFA & OFA & TFA & NFA & OFA & \\
\hline Learned helplessness & 46.1 & 71.5 & 39.0 & 148.41 & 297.06 & 114.03 & $203.118^{\mathrm{a}}$ \\
\hline
\end{tabular}

Abbreviations: NFA, never flood affected; OFA, once flood affected; TFA, twice flood affected.

${ }^{\mathrm{a}} p<0.01$.

Table 4 Results of Kruskal-Wallis test of comparing psychological wellbeing of family heads households in Kerala

\begin{tabular}{|l|l|l|l|l|l|l|l|}
\hline \multirow{2}{*}{ Variables } & \multicolumn{5}{|c|}{ Mean } & \multicolumn{3}{c|}{ Mean rank } \\
\cline { 2 - 8 } & NFA & OFA & TFA & NFA & OFA & TFA & \\
\hline Self-acceptance & 11.6 & 18.8 & 13.2 & 135.38 & 282.00 & 142.12 & $147.783^{\text {a }}$ \\
\hline Purpose in life & 13.0 & 14.2 & 14.7 & 151.15 & 190.08 & 218.27 & $24.687^{\text {a }}$ \\
\hline $\begin{array}{l}\text { Positive relations with } \\
\text { others }\end{array}$ & 11.3 & 19.8 & 14.8 & 112.00 & 285.03 & 162.47 & $173.844^{\text {a }}$ \\
\hline Personal growth & 12.0 & 19.5 & 16.9 & 108.98 & 270.79 & 179.73 & $142.250^{\text {a }}$ \\
\hline Environmental mastery & 12.3 & 14.6 & 13.8 & 150.86 & 211.14 & 197.50 & $21.631^{\text {a }}$ \\
\hline Autonomy & 11.0 & 19.6 & 16.4 & 86.75 & 288.23 & 184.52 & $219.881^{\text {a }}$ \\
\hline Psychological wellbeing & 71.3 & 106.5 & 89.6 & 106.00 & 288.18 & 165.31 & $185.270^{\text {a }}$ \\
\hline
\end{tabular}

Abbreviations: NFA, never flood affected; OFA, once flood affected; TFA, twice flood affected. ${ }^{a} p<0.01$. 
Table 5 Result of Kruskal-Wallis test of comparing proenvironment care behavior of family heads belonging to households in Kerala

\begin{tabular}{|l|l|l|l|l|l|l|l|}
\hline \multirow{2}{*}{ Variables } & \multicolumn{3}{|c|}{ Mean } & \multicolumn{3}{c|}{ Mean rank } \\
\cline { 2 - 8 } & NFA & OFA & TFA & NFA & OFA & TFA & \\
\hline Environmental action & 23.8 & 9.2 & 15.0 & 285.53 & 86.14 & 187.83 & $214.114^{\mathrm{a}}$ \\
\hline Political action & 10.4 & 4.8 & 5.4 & 279.87 & 129.71 & 149.92 & $146.351^{\mathrm{a}}$ \\
\hline Recycling & 10.8 & 4.4 & 5.3 & 285.09 & 128.51 & 145.90 & $163.794^{\mathrm{a}}$ \\
\hline Transportation & 9.2 & 3.9 & 5.4 & 265.78 & 117.23 & 176.49 & $124.291^{\mathrm{a}}$ \\
\hline Household setting & 9.7 & 4.1 & 8.4 & 248.21 & 88.80 & 222.50 & $159.404^{\mathrm{a}}$ \\
\hline Consumption & 14.5 & 5.6 & 7.3 & 288.16 & 115.22 & 156.12 & $178.694^{\mathrm{a}}$ \\
\hline
\end{tabular}

Abbreviations: NFA, never flood affected; OFA, once flood affected; TFA, twice flood affected.

${ }^{\mathrm{a}} \mathrm{p}<0.01$.

by the TFA group and the NFA group. All the pair-wise comparisons were significant in the case of subdimensions such as purpose in life dimension ( $K=24.687, p=0.0005)$, positive relationship with others ( $K=173.844, p=0.0005)$, personal growth $(K=142.250, p=0.0005)$, and autonomy ( $K=$ $219.881, p=0.0005)$; and total score of psychological wellbeing $(K=182.270, p=0.0005)$. In the case of self-acceptance ( $K=147.283, p=0.0005)$, the pair-wise comparisons were significant, except for comparisons between NFA group and TFA group $(K=0.494, p=0.621)$. In the case of environmental mastery ( $K=21.631, p=0.0005)$, the pair-wise comparisons were significant, except for comparisons between OFA group and TFA group ( $K=1.003, p=0.316$; - Table 5 ).

There were significant differences among the three groups in all dimensions and total scores of proenvironmental care behavior. The low score indicates high proenvironment care behavior. The common trend was that the OFA group had a high level of proenvironment care behavior, followed by the TFA group and the NFA group. In the case of environmental action $(K=214.114, p=0.0005)$, transportation $(K=124.291$, $p=0.0005)$, and consumption $(K=178.694, p=0.0005)$, pair-wise comparisons were significant. In the case of political action for environmental care behavior ( $K=146.351$, $p=0.0005)$, differences in pair-wise comparisons were significant, except between the OFA group and TFA group ( $K=$ $1.5, p=0.134)$. In the case of recycling of objects $(K=163.794$, $p=0.0005)$, differences in the pair-wise comparisons were significant, except between the OFA group and TFA group ( $K=1.296 .494, p=0.195)$. In the case of household settings $(K=159.404, p=0.0005)$, differences in the pair-wise comparisons were significant, except between NFA group and TFA group $(K=1.896, p=0.058$; - Table 6).

In the case of learned helplessness, ordinal position 1 indicates high level of learned helplessness of the group and ordinal positions 2 and 3 carry lower positions of the groups in order. In the case of psychological wellbeing and dimensions, ordinal position 1 indicates high level of wellbeing, and ordinal positions 2 and 3 carry lower positions in order. In the case of dimension of proenvironment care behavior, ordinal position 1 indicates, high level of environment care by the group, and ordinal positions 2 and 3 carry lower positions of the group in order.
Table 6 Summary of comparisons among the groups of family heads on learned helplessness, psychological wellbeing, and proenvironment care behavior

\begin{tabular}{|c|c|c|c|c|}
\hline Variables & Dimensions & NFA & OFA & TFA \\
\hline $\begin{array}{l}\text { Learned } \\
\text { helplessness }\end{array}$ & & 2 & 3 & 1 \\
\hline \multirow{7}{*}{$\begin{array}{l}\text { Psychological } \\
\text { wellbeing }\end{array}$} & & 3 & 1 & 2 \\
\hline & Self-acceptance & 2 & 2 & 1 \\
\hline & Purpose in life & 3 & 1 & 2 \\
\hline & $\begin{array}{l}\text { Positive relations } \\
\text { with others }\end{array}$ & 3 & 1 & 2 \\
\hline & Personal growth & 3 & 1 & 2 \\
\hline & $\begin{array}{l}\text { Environmental } \\
\text { mastery }\end{array}$ & 2 & 1 & 1 \\
\hline & Autonomy & 3 & 1 & 2 \\
\hline \multirow[t]{6}{*}{$\begin{array}{l}\text { Proenvironment } \\
\text { care behavior }\end{array}$} & $\begin{array}{l}\text { Environmental } \\
\text { action }\end{array}$ & & & \\
\hline & Political action & 2 & 1 & 1 \\
\hline & Recycling & 2 & 1 & 1 \\
\hline & Transportation & 3 & 1 & 2 \\
\hline & Household setting & 2 & 1 & 2 \\
\hline & Consumption & 3 & 1 & 2 \\
\hline
\end{tabular}

Abbreviations: NFA, never flood affected; OFA, once flood affected; TFA, twice flood affected.

Note: $1,2,3$, ordinal positions based on significance level. a $p<0.01$.

\section{Discussion}

We studied heads of families belonging to OFA, TFA, and NFA families in Kerala, 4 months after the flood in 2019. Analysis showed that TFA family heads showed significantly higher levels of learned helplessness in comparison to the other two groups. The heads of TFA families faced flood in 2018 and were in their recovery period. And the following year they reexperienced the flood and its consequences. Most of these families are living in vulnerable coastal areas in Kerala. Reparatory actions taken by households, organizations, and the government have limitations. And evacuation of their house or shifting living area is not easy for people 
since their life-savings, such as house and agriculture, of victims are locked in that location. This may lead to fear of frequent victimization which is not very easily avoidable. They continue to expect flood and hence are worried about its consequences. Studies among victims of multiple natural disasters has reported that the evacuation and financial lose severely affect victims' psychological well-being. ${ }^{15,19}$ Among these victims, the not only PTSD but also anxiety and depression are highly prevalent. ${ }^{20}$ Cherry et $\mathrm{al}^{28}$ studied middle aged and older adults who were victims of multiple flooding and found that there was significant elevations in symptoms of anxiety, depression, and posttraumatic stress among victims. Researchers observed that this is because of learned helplessness among victims due to the repeated and continuing threat of natural calamities. ${ }^{17}$

Another observation was that learned helplessness was significantly high among heads of NFA in comparison with OFA family heads. This might be because of resilience built by the OFA family heads, as well as the not experiencing flood in the second time in August 2019. The financial and material support offered by the Government, philanthropists, and other wealthy sects of society were huge, and many public schools, colleges, religious institutions, and so on joined hands in flood relief activities. This created a feeling that one can overcome such disasters because of the massive support given to them. They also developed the confidence that they can survive a further flood in future. People developed a greater hope in life and attachments to their own lives that were saved from the deaths caused by the flood. The NFA group never went through this support system that nourished positivity to the flood-affected group, and hence their psychological state remained the same. Since they hadn't faced a situation that made them realize how important and lucky it was to be alive, their level of satisfaction with life remained low and remained in sustained hopelessness.

In the case of psychological wellbeing, our findings are similar to that of learned helplessness. The OFA group enjoyed a significantly high level of psychological wellbeing. Perhaps the flood turned out to be a positive twist in the lives of the OFA group, as it boosted their psychological well-being to higher levels. Another interesting finding was that the TFA group had a high level of psychological wellbeing than the NFA group. This might have been because of the psychosocial awakening that happened to the TFA group when they were affected by flood. For the people of Kerala, the flood has had a social revival-impact. Community leaders, religious leaders, and mainstream news media, as well as social media, were surprised by and celebrated the communal harmony displayed by all sections of people including youth, fishing communities, religious organizations, nonresident Indians, and international organizations. The social support received by flood-affected people might have impacted their psychological wellbeing. While stating that there is a possibility that learned helplessness may become high and severely damage psychological wellbeing if these people face flood again. The social support may not alone safe-guard psychological wellbeing of victims.
In the case of the dimension of purpose of life (psychological wellbeing), the TFA group had the highest score in comparison to the OFA and NFA groups. The OFA group received a lot of help and support after the flood (2018), and they were safer when it flooded for a second time in 2019. This might have led to developing a sense of immunity from floods and being less concerned about future, same as the NFA group. As a concept, purpose of life is a more philosophical idea and it is the contentment with the whatever (even if this is less) one has and is about embracing its beauty. Moreover, the quest related to "purpose" is largely by those individuals whose existence is threatened and who live for the present. ${ }^{29}$ So it can be argued that the TFA group might have been be some steps ahead of the other groups in search of purpose. Some research has concluded that people may search for purpose in life by positively reframing adversities. ${ }^{30}$

In the case of dimensions of proenvironmental care behavior, such as environmental action, transportation, and consumption, we found that the OFA group had the highest level of environmental care, and they were followed by the TFA group and the NFA group in that order. In the case of dimensions, such as political action and recycling, the OFA and TFA groups had almost same level of environment care. And the status of NFA group remained as least cared group. In the case of dimension environmental care in handling household setting, the status of NFA and TFA groups is same. These trends show that floods might have created a greater need for better surroundings and to reverse the damage done by it. This could have resulted in a need for positive action for the betterment of their environmental surroundings and hence flood-affected people could develop a sense of care for their environment. These results also imply that the TFA population too had developed proenvironment attitude but after they had been affected by the flood for the second time, it created a fear of future floods in them. This in turn could have developed a sense of learned helplessness that their positive actions toward the environment will not be effective. The never flood-affected group, obviously, had never experienced a situation that would create awareness among them to maintain a healthy and clean environment. There have been several studies which have shown that exposure to natural calamities makes people more concerned about the health of nature than their never flood-affected counterparts. ${ }^{31,32}$ Spencer et al $^{33}$ noted a positive correlation between first-hand experience of flooding and environmental concern. Van der Linden ${ }^{23}$ also demonstrated that exposure to extreme weather events was positively linked to environmental risk perception. Another study ${ }^{24}$ found that people made more proenvironmental donations if they interpreted local temperature increases as evidence for global warming. Another study by Lang and Ryder ${ }^{34}$ also found that victims connect their negative experience with global warming and become more cautious about their environmental care. Similarly, Rudman et $\mathrm{al}^{35}$ found that students exposed to natural calamities show a more favorable attitude toward climate-protecting politicians.

According to the Challenge Model of Resilience, ${ }^{36}$ exposure to low and high level risks do not contribute to the resilience 
of individuals, but a moderate level of risk does. This model says that there is a curvilinear relationship between risk and positive outcomes. Moderate risk allows individuals to develop coping skills and employ resources to overcome these problems. Moderate level of risk (OFA) provided an opportunity to learn the process of overcoming risks than those who had less (NFA) and high (TFA) level of risks. This might be the reason for high level of wellness (psychological wellbeing and proenvironmental behavior) and low level of psychological morbidity among OFA group than the other two groups.

\section{Limitations}

This study has some limitations that need to be borne in mind while considering the above results. First, there were many more men participants in the study $($ men $=278$, women $=$ 90 ). This could have been because many of the heads of families in Kerala are men. Second, our study only covered five of the seven heavily affected (TFA) districts in Kerala. Thus the results may not be generalizable to the all affected districts. Third, our study included heads of families, assuming that their views are the best representative of victims but this may not always have been the case.

\section{Conclusion}

Our study found that learned helplessness was high among the TFA family heads in Kerala. We found that people who survived a natural disaster once had greater psychological wellbeing, proenvironment care behavior, and low learned helplessness as compared with the NFA and TFA groups. Hence, this study provides evidence that surviving a moderate amount of risk is perhaps necessary for better psychological wellbeing and that too many or too few risks in life can be detrimental to good psychological health.

Our study findings have the some important implications as well. First, the psychological impact of natural calamities on individuals and families have to be estimated and psychological interventions have to be offered at individual and family levels. Second, special attention must be given to the victims of frequent natural calamities to prevent negative psychological consequences. Third, disaster management teams must include mental health professionals and workers from allied disciplines. Fourth, proenvironment behavior among the victims of natural disasters and among those not affected has to be promoted to ensure positive interaction between humans and nature. Lastly, with adequate support, those affected by natural disasters, such as flood, can attain better psychological wellbeing and decreased learned helplessness. Much more research is warranted to extend these findings to natural disasters other than floods and to populations from other parts of India.

\section{Authors' Contributions}

The contributions of L. K. J. were in areas of conceptualization of the study, methods, tool selection, and data analysis, and preparing draft for publication, The contributions of M. R. were in aspects of translation of tools in Malayalam language, sampling and data collection, preparation of draft for publication and referencing. The contributions of S. G. were in conceptualization of the study, and preparation and revision of the draft.

\section{Ethical Approval}

This study was performed in line with the ethical principles enshrined in the Declaration of Helsinki.

\section{Funding}

None.

\section{Conflict of Interest}

None declared.

\section{References}

1 Felbermayr G, Groschl J. Naturally negative: the growth effects of natural disasters. J Dev Econ 2014;111:92-106

2 de Moel H, Jongman B, Kreibich H, Merz B, PenningRowsell E, Ward PJ. Flood risk assessments at different spatial scales. Mitig Adapt Strategies Glob Change 2015;20(6):865-890

3 Brouwer R, Akter S, Brander L, Haque E. Socioeconomic vulnerability and adaptation to environmental risk: a case study of climate change and flooding in Bangladesh. Risk Anal 2007;27(2):313-326

4 Kousky C. Impacts of natural disasters on children. Future Child 2016;1(26):73-92

5 Shultz JM, Russell J, Espinel Z. Epidemiology of tropical cyclones: the dynamics of disaster, disease, and development. Epidemiol Rev 2005;27:21-35

6 Madakasira S, O'Brien KF. Acute posttraumatic stress disorder in victims of a natural disaster. J Nerv Ment Dis 1987; 175(5):286-290

7 Krug EG, Kresnow M, Peddicord JP, et al. Suicide after natural disasters. N Engl J Med 1998;338(6):373-378

8 Stimpson JP. Flood and psychological well-being: direct, mediating, and moderating effects. J Mass Emerg Disasters 2005; $23: 27-48$

9 Math SB, Nirmala MC, Moirangthem S, Kumar NC. Disaster management: mental health perspective. Indian J Psychol Med 2015;37(3):261-271

10 Montazeri A, Baradaran H, Omidvari S, et al. Psychological distress among Bam earthquake survivors in Iran: a populationbased study. BMC Public Health 2005;5:4

11 Kar N, Jagadisha, Sharma P, Murali N, Mehrotra S. Mental health consequences of the trauma of super-cyclone 1999 in orissa. Indian J Psychiatry 2004;46(3):228-237

12 Ghaffari-Nejad A, Ahmadi-Mousavi M, Gandomkar M, Reihani-Kermani $\mathrm{H}$. The prevalence of complicated grief among Bam earthquake survivors in Iran. Arch Iran Med 2007; 10(4):525-528

13 John PB, Russell S, Russell PS. The prevalence of posttraumatic stress disorder among children and adolescents affected by tsunami disaster in Tamil Nadu. Disaster Manag Response 2007; $5(1): 3-7$

14 Kumar MS, Murhekar MV, Hutin Y, Subramanian T, Ramachandran V, Gupte MD. Prevalence of posttraumatic stress disorder in a coastal fishing village in Tamil Nadu, India, after the December 2004 tsunami. Am J Public Health 2007;97(1):99-101

15 Mason V, Andrews H, Upton D. The psychological impact of exposure to floods. Psychol Health Med 2010;15(1):61-73

16 Demski C, Capstick S, Pidgeon N, Sposato RG, Spence A. Experience of extreme weather affects climate change 
mitigation and adaptation responses. Clim Change 2017;140(2): 149-164

17 Sharma S, Sharma S, Chandra M, Mina S, Balhara YPS, Verma R. Psychological well-being in primary survivors of Uttarakhand disaster in India. Indian J Soc Psychiatry. 2015;31(1):29-36

18 Othman AZ, Dahlan A, Borhani SN, Rusdi H. Posttraumatic stress disorder and quality of life among flood disaster victims. Procedia Soc Behav Sci 2016;234:125-134

19 Bland SH, O'Leary ES, Farinaro E, Jossa F, Trevisan M. Long-term psychological effects of natural disasters. Psychosom Med 1996;58(1):18-24

20 Stanko K, Calamia K, Cherry K, Elliott E. Post-traumatic stress and cognitive functioning after disaster: is sleep disturbance and impairment responsible? Innov Aging 2018;2(1):251

21 Government of Kerala. Post Disaster Needs Assessment Floods and Landslides - August 2018. Available at: https:// reliefweb.int/report/india/kerala-post-disaster-needs-assessment-floods-and-landslides-august-2018. Accessed October 21, 2020

22 Pooja VK, Nagalakshami K. Stress, anxiety and depression among flood affected people in Kerala. Int J Educ Psychol Res. 2018;7(4):78-80

23 Van der Linden S. The social-psychological determinants of climate change risk perceptions: towards a comprehensive model. J Environ Psychol 2015;41:112-124

24 Li Y, Johnson EJ, Zaval L. Local warming: daily temperature change influences belief in global warming. Psychol Sci 2011;22(4):454-459

25 Quinless FW, Nelson MA. Development of a measure of learned helplessness. Nurs Res 1988;37(1):11-15

26 Ryff CD. Psychological well-being in adult life. Curr Dir Psychol Sci 1995:4:99-104
27 Halkos G, Gkargkavouzi A, Matsiori S. A multi-dimensional measure of environmental behavior: Exploring the predictive power of connectedness to nature, ecological worldview and environmental concern. Social Indicators Research 2018;143:859-879

28 Cherry KE, Stanko KE, Calamia MR, Elliott EM. Psychological well-being after multiple disaster exposures: hurricane Katrina and the great flood of 2016. Innov Aging 2018;2(1):45-46

29 Frankl VE, Man's Search for Meaning: An Introduction to Logotherapy. New York, NY: Simon \& Schuster; 1984

30 Schaefer SM, Morozink Boylan J, van Reekum CM, et al. Purpose in life predicts better emotional recovery from negative stimuli. PLoS One 2013;8(11):e80329

31 Whitmarsh L. Are flood victims more concerned about climate change than other people? The role of direct experience in risk perception and behavioural response. J Risk Res 2008;11:351-374

32 Hornsey MJ, Harris EA, Bain PG, Fielding KS. Meta-analysis of the determinants and outcomes of belief in climate change. Nat Clim Chang 2016;6:622-626

33 Spencer A, Poorting W, Butler C, Pidgeon NS. Perceptions of climate change and willingness to save energy related to flood experience. Nat Clim Chang 2011;1:46-49

34 Lang C, Ryder JD. The effect of tropical cyclones on climate change engagement. Clim Change 2016;135:625-638

35 Rudman LA, McLean MC, Bunzl M. When truth is personally inconvenient, attitudes change: the impact of extreme weather on implicit support for green politicians and explicit climate-change beliefs. Psychol Sci 2013;24(11):2290-2296

36 Garmezy N, Masten AS, Tellegen A. The study of stress and competence in children: a building block for developmental psychopathology. Child Dev 1984;55(1):97-111 